\title{
HISTÓRIA, REGIÃO E NATUREZA: DELIMITAÇÃO REGIONAL EM HISTÓRIA AMBIENTAL
}

\section{HISTORY, REGION AND NATURE: REGIONAL DELIMITATION IN ENVIRONMENTAL HISTORY}

\author{
Caroline Lisboa dos Santos de Lima'
}

\begin{abstract}
RESUMO: Este artigo discute o conceito de região levando em consideração o diálogo existente entre a História e a Geografia. Analisa critérios relevantes para a definição de um recorte espacial baseado em elementos naturais, porém, afastado do determinismo geográfico, bem como, busca compreender a interface entre a História Regional e a História Ambiental. Por fim, a título de exemplificação, define uma região que não se restringe a um espaço delimitado política e administrativamente ou geograficamente, mas sim, pela área de influência de um rio, a partir das relaçóes estabelecidas entre este e a sociedade que o cerca.
\end{abstract}

PALAVRAS-CHAVE: Região. História Ambiental. Determinismo Geográfico.

ABSTRACT: This article discusses the concept of region considering the existing dialogue between History and Geography. It analyzes criteria relevant to the definition of a spatial cut based on natural elements, however, away from geographic determinism, as well as, it seeks to understand the interface between Regional History and Environmental History. Finally, by way of example, it defines a region that is not restricted to a politically-administratively or geographically defined area, but rather by the area of influence of a river, based on the relations established between it and the society that surrounds it.

KEYWORDS: Region. Environmental History, Geographical, Determinism.

São muitas as discussões em torno da História Regional e da delimitação de uma regiáo. Da mesma forma, a História Ambiental tem se mostrado promissora ao buscar a compreensão da complexa relação entre o homem e o ambiente que o cerca. Sendo assim, o presente artigo tem o propósito de discutir as articulaçóes existentes entre História Regional e História Ambiental, utilizando-se da delimitação regional de uma pesquisa referente ao rio Passo Fundo, localizado na cidade que leva seu nome, no estado do Rio Grande do Sul, Brasil.

$\mathrm{O}$ artigo é composto por quatro partes. Inicialmente, discute-se o conceito de regiáo e a interdisciplinaridade em torno dele. $\mathrm{Na}$ segunda parte procura-se compreender as relaçóes entre a História Regional e a História Ambiental. A terceira aborda alguns critérios

Mestranda em História, Universidade de Passo Fundo/UPF. Bolsista Capes. E-mail: a.caroline.lisan@gmail.com 
relevantes para a definição de um recorte regional baseado em elementos da natureza, ressaltando a importância de manter as análises distantes de um possível determinismo geográfico. A quarta e última parte exemplifica um recorte regional que não se restringe a um espaço delimitado política-administrativamente ou geograficamente, mas sim, pelas relaçóes estabelecidas entre a sociedade e o rio Passo Fundo.

\section{HISTÓRIA REGIONAL E O CONCEITO DE REGIÃO}

Durante suas pesquisas, os historiadores são requisitados a fazer diversas opções que, sejam elas temáticas, teóricas ou metodológicas tornam o produto do conhecimento distinto, heterogêneo, com um caminho de possibilidades a ser trilhado. Ao escrever a história, o pesquisador inexoravelmente opta por um tema, um período e uma regiáo a ser estudada. Ter clareza dessas definiçóes e da escolha de conceitos é fundamental para que se possa fazer um trabalho coerente e significativo. $\mathrm{O}$ conceito de regiáo vem sendo delimitado e discutido pela academia e, apesar de parecer simples, não o é, pois engloba possibilidades diversas. A primeira área do conhecimento a discutir o conceito de regiáo foi a Geografia. A princípio, os geógrafos limitaram-se a análises a partir do conteúdo natural e, segundo o sociólogo Pierre Bourdieu, dando "demasiada importância aos fenômenos físicos" $(1998,108)$. Geógrafos pertencentes a escola geográfica crítica ${ }^{2}$ contribuíram para o avanço do tema quando consideraram que, além de estar relacionado diretamente à noção de espaço, a regiáo deve ser entendida como produto direto da ação humana. Além dos geógrafos, outras áreas do conhecimento passaram a conceituar região. Para os economistas a regiáo seria determinada pelos fluxos econômicos. Para os sociólogos e etnólogos seria definida por representaçóes mentais (BOURDIEU, 1998, p. 109). A tentativa de delinear o que é uma regiáo acabou abrangendo diversas áreas do conhecimento e é notório que, como considerou José D’Assunção Barros "a interdisciplinaridade entre a História e a Geografia é estabelecida, entre outros aspectos, através de conceitos como "espaço", "território" e "regiáo"” (2006, p. 4). Como a conceituação de regiâo inclui a compreensão de outras definições, fez-se necessário entender o significado de espaço e território, e nesse sentido, o geógrafo Claude Raffestin deu uma importante contribuição quando estabeleceu uma distinção entre os termos que por vezes podem ser confundidos. De acordo com o autor "o território se forma a partir do espaço, é o resultado de uma açáo conduzida por um ator [...]. Ao se apropriar de um espaço, concreta ou abstratamente [...], o ator 'territorializa' o espaço" (RAFFESTIN, 1993, p. 143). O historiador Durval Albuquerque Jr. considerou que:

Nossos territórios existenciais são imagéticos. Eles nos chegam e são subjetivados por meio da educaçáo, dos contatos sociais, dos hábitos, ou seja, da cultura, que nos faz pensar o real como totalizaçóes abstratas. Por isso, a história se assemelha ao teatro, onde os atores,

Corrente geográfica que procurava analisar além das características físicas naturais, mas também sociais, como afirmou Visentini $(2004,223)$ utilizando-se da "criticidade entendida como uma leitura do real - isto é, do espaço geográfico - que não omitia as suas tensóes e contradiçóes, tal como fazia e faz a geografia tradicional, que ajude a esclarecer a espacialidade das relaçóes de poder e de dominação". 
agentes da história, só podem criar à condição de se identificarem com figuras do passado, de representarem papéis, de vestirem máscaras, elaboradas permanentemente (ALBUQUERQUE JR., 2009, p. 27).

Assim, o território é uma produção, feita pelos sujeitos, a partir do espaço e de suas experiências sociais. Então, a partir disso, o que é região? E como delimitá-la? De acordo com Adelar Heinsfeld são muitos os adjetivos que acompanham o vocábulo região, podendo-se falar de "região natural", "região histórica", "região geográfica", "região econômica", "região urbana", "região homogênea", "região polarizada" [...] (HEINSFELD, 2010, 5). Há uma ampla gama de possibilidades de delimitação regional que fogem à tradicional divisão político-administrativa, quanto a isso, Barros conclui:

Uma determinada prática cultural [...] pode gerar um território específico que nada tenha a ver com o recorte administrativo de uma paróquia ou município, misturando pedaços de unidades paroquiais distintas ou vazando municípios. Do mesmo modo, uma realidade econômica ou de qualquer outro tipo não coincide necessariamente com a região geográfica no sentido tradicional. A crítica aos modelos de recorte regional-administrativo, ou de recortes geográficos [...] não surgiram apenas das novas buscas historiográficas, mas também de desenvolvimentos que se deram no próprio seio da Geografia Humana (BARROS, 2006, p. 13).

Portanto, para os historiadores, o conceito de região não pode ser definido sem levar em consideração sua carga histórica e sua delimitação não pode compreender apenas questóes de natureza física, jurídico-administrativa ou econômica. Sobre isso, Albuquerque Jr. afirma que:

ela (região) remete a uma visão estratégica do espaço, ao seu esquadrinhamento, ao seu recorte e à sua análise, que produz saber. Ela é uma noçáo que nos envia a um espaço sob domínio, comandado. Ela remete, em última instância, a regio (rei). Ela nos póe diante de uma política de saber, de um recorte espacial das relaçôes de poder. Pode-se dizer que ela é um ponto de concentração de relaçôes que procuram traçar uma linha divisória entre elas e o vasto campo do diagrama de forças operantes num dado espaço. Historicamente, as regiôes podem ser pensadas como a emergência de diferenças internas à nação, no tocante ao exercício do poder, como recortes espaciais que surgem dos enfrentamentos que se dão entre os diferentes grupos sociais, no interior da nação. A regionalização das relaçôes de poder pode vir acompanhada de outros processos de regionalização, como o de produção, o das relaçôes de trabalho e o das práticas culturais, mas estas não determinam sua emergência. A região é produto de uma batalha, é uma segmentação surgida no espaço dos litigantes. As regiôes são aproveitamentos estratégicos diferenciados do espaço. Na luta pela posse do espaço ele se fraciona, se divide em quinhóes diferentes para os diversos vencedores e vencidos; assim, a regiẫo é o botim de uma guerra (ALBUQUERQUE JR., 2009, pp. 25-26).

A região, deste modo, é uma criação do indivíduo, um recorte espacial feito a partir de relaçóes de poder, deve ser considerada como uma construção social, produto das açóes, experiências e vivências de seus agentes históricos, e como um espaço social construído pelos sujeitos, é passível de inúmeros recortes de caráter administrativo, geográfico, histórico, ecológico, econômico ou mesmo psicológico, como destacou a autora María Rosa Carbonari:

De ese modo, la región, como entidad concreta, se concibe como resultante de múltiples determinaciones y se caracteriza por una naturaleza transformada por herencias culturales y materiales y por una determinada estructura social con sus propias contradicciones. Es 
particular e nel sentido de una especificación de la totalidad espacial de la cual forma parte; es decir, es la realización de un proceso histórico general en un cuadro territorial menor, donde se combinan lo general y lo particular (CARBONARI, 2009, p. 28).

Compreende-se agora a região não apenas como um espaço territorial, mas sim um espaço social, uma construção determinada pelos mais diversos aspectos. Sendo assim, é importante ter clareza da razão e da metodologia utilizada para a delimitação de um estudo em determinado espaço regional. Como considerou Milton Santos (1997, p. 46) "estudar uma região significa penetrar num mar de relaçôes, formas, funçôes, organizaçóes, estruturas etc., com seus mais distintos niveis de interação e contradição".

\section{POR UMA HISTÓRIA AMBIENTAL REGIONAL SEM DETERMINISMOS}

A História Ambiental tem como premissa o entendimento da relação entre os seres humanos e o ambiente que os cerca e, para tal, não se detém a análise da trajetória histórica do meio biofísico, mas sim da complexa interação estabelecida entre o ambiente e o homem, e as interferências dos mais diversos agentes nesse contexto. Assim, é muito importante afastar-se de análises deterministas, análises essas que reduzem a compreensão do conjunto e simplificam as relaçóes que se estabelecem entre as sociedades e seu meio. Nas palavras de José Augusto Pádua:

\footnotetext{
Não se trata, portanto, de reduzir a análise histórica ao biofísico, como se esse aspecto fosse capaz de explicar todos os outros, mas de incorporá-lo de maneira forte - junto com outras dimensóes econômicas, culturais, sociais e políticas - na busca por uma abordagem cada vez mais ampla e inclusiva de investigaçáo histórica. $\mathrm{O}$ crescimento acadêmico recente da história ambiental, ao menos em parte, se explica exatamente por sua capacidade concreta para ampliar a análise histórica e trazer novas perspectivas para o estudo de antigos problemas historiográficos (PÁDUA, 2010, p. 94).
}

As pesquisas em História Ambiental abordam diferentes paisagens: sertóes, montanhas, florestas, outros diferentes tipos de vegetaçóes, bacias hidrográficas, praias, lagos, rios, etc., sempre procurando compreender primeiramente a constituição física natural desse ambiente, as interações humanas históricas com ele e suas consequências.

Pesquisadores como Donald Worster e Roderick Nash procuram compreender teórico e metodologicamente o fazer da História Ambiental. Outros importantes autores também se tornaram referência, a partir de seus estudos sobre o relacionamento das sociedades com o ambiente, Warren Dean é um deles. Esse historiador norte-americano pesquisou entre outros temas, a regiáo amazônica publicando o livro A luta pela borracha no Brasil: um estudo de história ecológica, de 1989, e posteriormente a Mata Atlântica na obra Aferro e fogo: a história e a devastação da Mata Atlântica brasileira, de 1996,em que estuda o processo de degradação desse bioma, identificando como os diversos agentes: industriais, mineradores, agricultores, índios, missionários, entre outros, contribuíram para as mudanças desse ambiente. Outra importante contribuição vem do historiador José Augusto Drummond que analisa através da obra Devastação e preservação ambiental:os parques nacionais do Estado do Rio de Janeiro, de 1997, as características naturais e sociais dos parques nacionais fluminenses. 
A partir dos anos 2000 a historiografia brasileira passa por um processo de ampliação em relação aos temas ambientais. Com o surgimento de diversos autores que através de suas pesquisas puderam contribuir para o alargamento das análises referentes à História Ambiental e devido à grande diversidade natural brasileira, abriu-se uma grande gama de questóes e debates. A este respeito Paulo Henrique Martinez afirma que:

A História Ambiental no Brasil encerra grandes possibilidades que, desde logo, afugentam os riscos de uma "historiografia de imitação" ou de mimetismo acadêmico das modas intelectuais europeias e norte-americanas, pois contém inúmeras perspectivas de trabalho que desafiam a imaginação inventiva e a criatividade dos historiadores (MARTINEZ, 2005, p. 29).

Entre os importantes nomes a destacar, está o do especialista em história e política ambiental José Augusto Pádua que na obra de 2002, Um sopro de destruição: pensamento político e crítica ambiental no Brasil escravista, examina textos de 1786 e 1888 sobre as consequências do sistema escravista para o ambiente. Gilmar Arruda igualmente contribuí de maneira relevante através de suas obras com Cidades e sertóes: entre a história e a memória, A natureza dos rios: história, memória e territórios, entre muitas outras que tratam das relaçóes humanas com seu meio.

O historiador Donald Worster, um dos principais nomes da História Ambiental, compreende que ao realizar um estudo pertencente a esse campo, é necessário considerar três níveis distintos de interação:

O primeiro trata do entendimento da natureza propriamente dita, tal como se organizou e funcionou no passado. [...] O segundo nível da história ambiental introduz o domínio socioeconômico na medida em que este interage com o meio ambiente. Por fim, formando um terceiro nível de análise [...] vem aquele tipo de interação mais intangível e exclusivamente humano, puramente mental ou intelectual, no qual percepçôes, valores éticos, leis, mitos e outras estruturas de significação se tornam parte do diálogo de um indivíduo ou de um grupo com a natureza (WORSTER, 1991, pp. 201-202).

Portanto, é muito importante que o pesquisador que se propóe a investigar dentro do campo da História Ambiental assuma o compromisso de afastar-se de análises deterministas, análises essas que reduzem a compreensão do conjunto e simplificam as relaçóes que se estabelecem entre as sociedades e seu meio.

Mas então, como delimitar uma regiáo baseando-se em um elemento natural sem que somente ele determine as delimitaçóes do espaço regional a ser estudado? Antes de propor um caminho para essa questão, é importante entender o que significa o determinismo geográfico e como ele pode afetar os estudos de História Ambiental.

O determinismo geográfico tem raízes profundas na história, tanto mundial como brasileira. Muitos autores utilizaram-se desse tipo de argumento para estabelecer a relação entre os homens e a natureza. Foram as ideias de Friedrich Ratzel, geógrafo e etnólogo alemão, considerado por muitos de seus seguidores como grande divulgador do determinismo geográfico, que embasaram as discussóes sobre o tema. De acordo com Antônio Moraes:

O principal livro de Ratzel, publicado em 1882, denomina-se Antropogeografia -fundamentos da aplicação da Geografia à História; pode-se dizer que esta obra funda a Geografia Humana. Nela, Ratzel definiu o objeto geográfico como o estudo da influência que as condiçóes naturais 
exercem sobre a humanidade. Estas influências atuariam, primeiro na fisiologia (somatismo) e na psicologia (caráter) dos indivíduos e, através destes, na sociedade. Em segundo lugar, a natureza influenciaria a própria constituição social, pela riqueza que propicia, através dos recursos do meio em que está localizada a sociedade. A natureza também atuaria na possibilidade de expansão de um povo, obstaculizando-a ou acelerando-a. E ainda nas possibilidades de contato com outros povos, gerando assim o isolamento e a mestiçagem. Ratzel realizou extensa revisão bibliográfica, sobre o tema das influências da natureza sobre o homem, e concluiu criticando as duas posiçóes mais correntes: a que nega tal influência, e a que visa estabelecê-la de imediato (MORAES, 2005, p. 19).

Partindo desses princípios, os discípulos de Ratzel acabaram utilizando suas conclusóes para fundar a doutrina baseada no que se chamou de "determinismo geográfico". De acordo com Moraes eles "orientaram seus estudos por máximas, como "as condiçōes naturais determinam a História, ou "o homem é um produto do meio" - empobrecendo bastante as formulaçóes de Ratzel, que falava de influências" (2005, p. 20). No Brasil, as discussóes sobre o determinismo predominaram no debate em torno do conceito de raça. As discussóes da ação do clima e do relevo sobre as populaçóes esteve presente no pensamento geográfico brasileiro a partir do final do século XIX e início do XX. De acordo com Rafael Ribeiro:

Dessa forma, do ponto de vista do discurso regional, podemos falar na existência de um determinismo geográfico nordestino, que acompanha até hoje o imaginário da região, apesar de teorias deterministas há muito serem rechaçadas por grande parte dos geógrafos (RIBEIRO, 1999, p. 61).

$\mathrm{Na}$ contramão das análises estabelecidas pelo determinismo geográfico, encontramos autores como o geógrafo francês Paul Vidal de La Blache, considerado o fundador da geografia francesa moderna e da corrente francesa de Geografia Humana.Crítico de Ratzel, Vidal de la Blache, de acordo com Moraes:

Criticou a minimização do elemento humano, que aparecia como passivo nas teorias de Ratzel. Nesse sentido, defendeu o componente criativo (a liberdade) contido na ação humana que não seria apenas uma resposta às imposiçóes do meio. Assim, valorizou a História, valendose de sua formação acadêmica de historiador. Aqui, residiu sem dúvida a contribuição mais importante de Vidal de La Blache para o desenvolvimento do pensamento geográfico. Entretanto, apesar de aumentar a carga humana do estudo geográfico, este autor não rompeu totalmente com uma visão naturalista, pois diz explicitamente: "a Geografia é uma ciência dos lugares, não dos homens". Desta forma, o que interessaria à análise seria o resultado da ação humana na paisagem, e náo esta em si mesma. [...] Atacou a concepçấo fatalista e mecanicista da relação entre os homens e a natureza. Assim, atingiu diretamente a ideia da determinação da História pelas condiçóes naturais. Vidal vai propor uma postura relativista, no trato dessa questão, dizendo que tudo o que se refere ao homem "é mediado pela contingência". Este posicionamento, aceito por seus seguidores, fez com que a Geografia francesa abandonasse qualquer intento de generalizar (MORAES, 2005, p. 24).

A partir das concepçóes de Vidal "a natureza passou a ser vista como possibilidades para a ação humana; dai o nome de Possibilismo dado a esta corrente por Lucien Febvre" (MORAES, 2005, p. 24). La Blache estabeleceu um importante diálogo entre a Geografia e a História terminando por deixar:

Influências também no pensamento dos historiadores, notadamente daqueles de língua francesa, no que toca à concepção deste com respeito à Geografia, e sua relação com a História. 
Aí, desempenharam papel destacado as colocaçóes de Lucien Febvre. Este autor escreveu uma obra, que se tornou clássica, A Terra e a evolução humana, na qual apresenta as ideias de La Blache, confrontadas com as de Ratzel, desenvolvendo-as e defendendo-as das críticas levantadas contra a Geografia Humana, por E. Durkheim. Foi Febvre que criou os termos Determinismo e Possiblismo, assumindo integralmente o conteúdo deste último. Assim, da proposta vidalina, desdobrou-se também uma Geografia Histórica (MORAES, 2005, p. 29).

Partindo das consideraçóes feitas tanto pelos autores deterministas quanto pelos possibilistas, é fundamental que o pesquisador que se propóe a realizar estudos de história ambiental, tenha equilíbrio na forma de abordagem que irá assumir, como esclarece o historiador José Augusto Pádua, quando produz uma pesquisa de História Ambiental:

Não se trata [...] de reduzir a análise histórica ao biofísico, como se esse aspecto fosse capaz de explicar todos os outros, mas de incorporá-lo de maneira forte - junto com outras dimensôes econômicas, culturais, sociais e políticas - na busca por uma abordagem cada vez mais ampla e inclusiva de investigação histórica. O crescimento acadêmico recente da história ambiental, ao menos em parte, se explica exatamente por sua capacidade concreta para ampliar a análise histórica e trazer novas perspectivas para o estudo de antigos problemas historiográficos (PÀDUA, 2010, p. 94).

É certo que, as condições naturais podem gerar diferentes tipos de percepções e possibilidades para as populaçóes. Porém, também é certo que o ser humano é um ser extremamente diverso e capaz de ações e adaptaçóes surpreendentes. Assim, não será exclusivamente a localização de um rio, de uma montanha, ou de uma floresta que irá determinar o modo de vida de populaçóes inteiras. Náo se pode negligenciar a influência que as condições naturais e os fatores geográficos podem exercer sobre as sociedades, mas não será isso o que determinará do que as pessoas seráo capazes. Deve-se reconhecer sua influência, que é inegável, mas jamais permitir que o ambiente determine análises e conclusóes. Pois, como muito bem escreveu Marc Bloch, o historiador não pode legitimar "a superstiçâo da causa única" seja ela qual for (2001, p. 157) mas sim, procurar sempre combinar todos os elementos intrínsecos às sociedades sejam eles políticos, culturais, naturais, etc.

\section{DELIMITAÇÃO REGIONAL EM UM ESTUDO DE HISTÓRIA AMBIENTAL}

Muitos estudos têm surgido contendo temáticas referentes ao meio ambiente e as relaçóes que os seres humanos estabelecem com ele, sejam sobre o solo, clima, fauna, flora, movimentos geológicos, bacias hidrográficas, etc., procuram compreender as consequências ambientais do agir humano sobre o ambiente e vice-versa. Neste artigo, apresenta-se um exemplo de delimitação regional em uma pesquisa de História Ambiental que diz respeito à relação estabelecida historicamente entre uma população e um rio, o rio Passo Fundo, localizado na cidade que leva seu nome, no estado do Rio Grande do Sul, Brasil. $\mathrm{O}$ rio Passo Fundo tem sua nascente no distrito de Povinho Velho, nas proximidades com a divisa do município de Mato Castelhano. O rio integra uma importante bacia hidrográfica do estado do Rio Grande do Sul, a Bacia Hidrográfica do rio Passo Fundo que engloba um total de 30 municípios do estado. Compreende-se por bacia hidrográfica, como definido por Barrella: 
O conjunto de terras drenadas por um rio e seus afluentes, formada nas regióes mais altas do relevo por divisores de água, onde as águas das chuvas, ou escoam superficialmente formando os riachos e rios, ou infiltram no solo para formação de nascentes e do lençol freático (BARRELLA et. al., 2001, p. 188).

Partindo desses dados, é importante destacar que o recorte regional utilizado para o estudo não corresponde à delimitação político-administrativa do município, nem tampouco à Bacia Hidrográfica do rio Passo Fundo, como vê-se na Figura 1.

Figura 1: Bacia hidrográfica do rio Passo Fundo

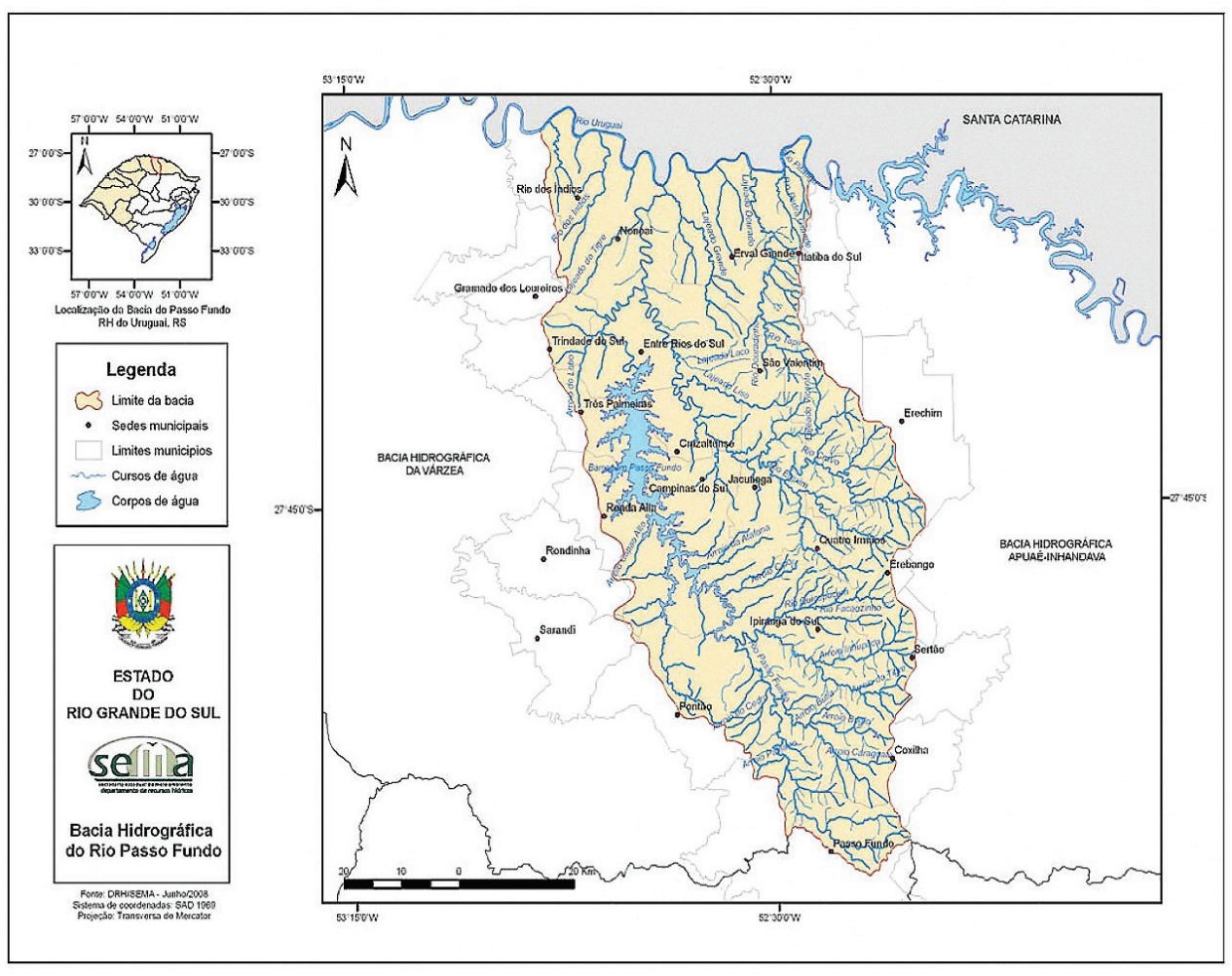

Fonte: DRH/SEMA. Relatório anual de recursos hídricos no RS, 2007.

A pesquisa a que se refere essa delimitação regional se propóe a ampliar as abordagens e análises históricas do município de Passo Fundo levando em consideração as relações, interaçóes e açóes diretas em torno do rio. Possivelmente a necessidade de estar próximo à água, recurso natural táo importante, tenha sido um dos fatores que influenciou à fixação dos primeiros grupos humanos onde hoje encontra-se o município de Passo Fundo. Desde a ocupação do território por comunidades indígenas, passando pela chegada dos primeiros ibéricos na região, a constituição de Passo Fundo como município e até hoje, os seres humanos que fizeram parte desta paisagem influenciaram e foram influenciados por ela. Muito se escreveu sobre a história da cidade de Passo Fundo. Ao longo do tempo diversos autores procuraram compreender a formação do município a partir de análises sobre seus habitantes, sua trajetória política, seu desenvolvimento econômico, industrial, urbano, etc. Dentre estes autores podemos destacar Francisco Antonino Xavier e Oliveira 
em 1908 inaugurou os estudos sobre Passo Fundo em sua série de livros intitulados Annaes do município de Passo Fundo, em que trata de alguns aspectos históricos, geográficos e culturais da cidade. Sobre as características hidrográficas do local já dizia:

A riqueza hidrográfica do município é tal, que nenhuma outra região do mundo poderá em igual área apresentar maior número de cursos nem mais feliz distribuição do precioso liquido tão necessário aos três reinos da natureza. A não ser pelo espinhaço da Coxilha Geral e suas ramificaçôes, raramente o viajante andará mais de um quilômetro sem encontrar água abundante e deliciosa, já nos arroios e rios, que em todas as direçóes deslizam em busca das principais artérias hidrográficas, já nos vigorosos olhos d'água que por toda a parte rebentar a ferver, como que acionados pelo calor de um fogo invisível, muitos deles sem escoadouro pela superfície do solo, e sim por condutos subterrâneos (OLIVEIRA, 1990, p. 72).

Especificamente sobre o rio Passo Fundo, o autor destacou:

Este rio, antigamente chamado Uruguai-mirim, nasce na mesma coxilha que o do Peixe [Piraçucê], banha a cidade do mesmo nome, os Campos da Entrada, do $3^{\circ}$ distrito [Coxilha], do Butiá, dos Quatro Irmãos, do Valinho, do Bugre, do Sarandi, do Arvoredo e o sertão do Uruguai, chegando a esse rio com um curso de cerca de 200 quilômetros. Recebe, pela margem direita, o Miranda [arroio], o Butiá, o do Facão com seu afluente Teixeira, o do Meio, o dos Pinheiros Altos, o do Carajá, o do Veado, o do Carreiro e do Erechim, que é o maior de todos e tem um curso cerca de 100 quilômetros; e, pela esquerda, o dos Moinhos, o Passo D'Areia, o Bugre, o Sarandi e da Divisa, além de outros no município de Palmeira (OLIVEIRA, 1990, p. 75).

Outro autor que dedicou seu tempo aos escritos sobre Passo Fundo foi Jorge Cafruni que, em 1966 escreveu a obra Passo Fundo das Missóes. Sobre o papel dos rios da região, destacou:

Para a história de Passo Fundo, os rios que desempenharam um papel de relêvo, como marcos assinaladores, no panorama geográfico, são os seguintes: Rio Jacuí, Carreiro, do Peixe, da Várzea, Jacuí-mirim e respectivos afluentes; o rio Uruguai-mirim, atual Passo Fundo, era só conhecido, na época de que tratamos, pelos silvícolas, pois que os elementos civilizados o tinham apenas como arroio, conhecendo-o poucas léguas, a partir de suas nascentes, de modo que não assinalaram como ponto de referência; já o rio da Várzea, então chamado Uruguaipitâ, era, pelo contrário, alvo de citaçáo, principalmente pelos demarcadores do século dezoito, em busca do Peperi-guaçu (CAFRUNI, 1966, p. 24).

Apesar de tratarem do rio Passo Fundo, mesmo que de maneira breve, nenhum desses autores analisa esse ambiente na perspectiva da História Ambiental, procurando compreender quais as interaçóes humanas em torno do rio Passo Fundo. É pela busca por preencher essa lacuna historiográfica e ainda, o estudo das políticas públicas referentes ao tema que essa pesquisa se justifica. Ao avaliar as políticas públicas e os usos dados ao rio Passo Fundo no período que compreende 1934 (ano de decreto do Código de Águas brasileiro) a 2007 (ano em que o rio é declarado Patrimônio Natural e Paisagístico do município) pretende-se compreender e explicar o processo histórico de uso do rio, em que medida e de que forma interesses socioeconômicos interagiram com esse ambiente, bem como o papel que as legislaçóes tiveram nessa trajetória. Partindo dessas proposiçóes, o recorte regional náo poderia compreender apenas aspectos político-administrativos, nem tampouco apenas naturais, pois não conseguiriam abarcar todas as relações estabelecidas 
entre as sociedades e o rio nos mais diversos períodos históricos. Diante disso, a delimitação irá corresponder ao trajeto feito pelo rio Passo Fundo desde a sua nascente, às proximidades do percurso que o rio faz em direçáo ao norte do estado, aos locais ocupados por populaçóes humanas que interagiram e interagem com o rio, à parte de sua bacia hidrográfica, contudo, tendo como limite a divisa do município de Passo Fundo com o município de Pontão, como mostra a Figura 2.

Figura 2: Delimitação regional utilizada para a pesquisa.

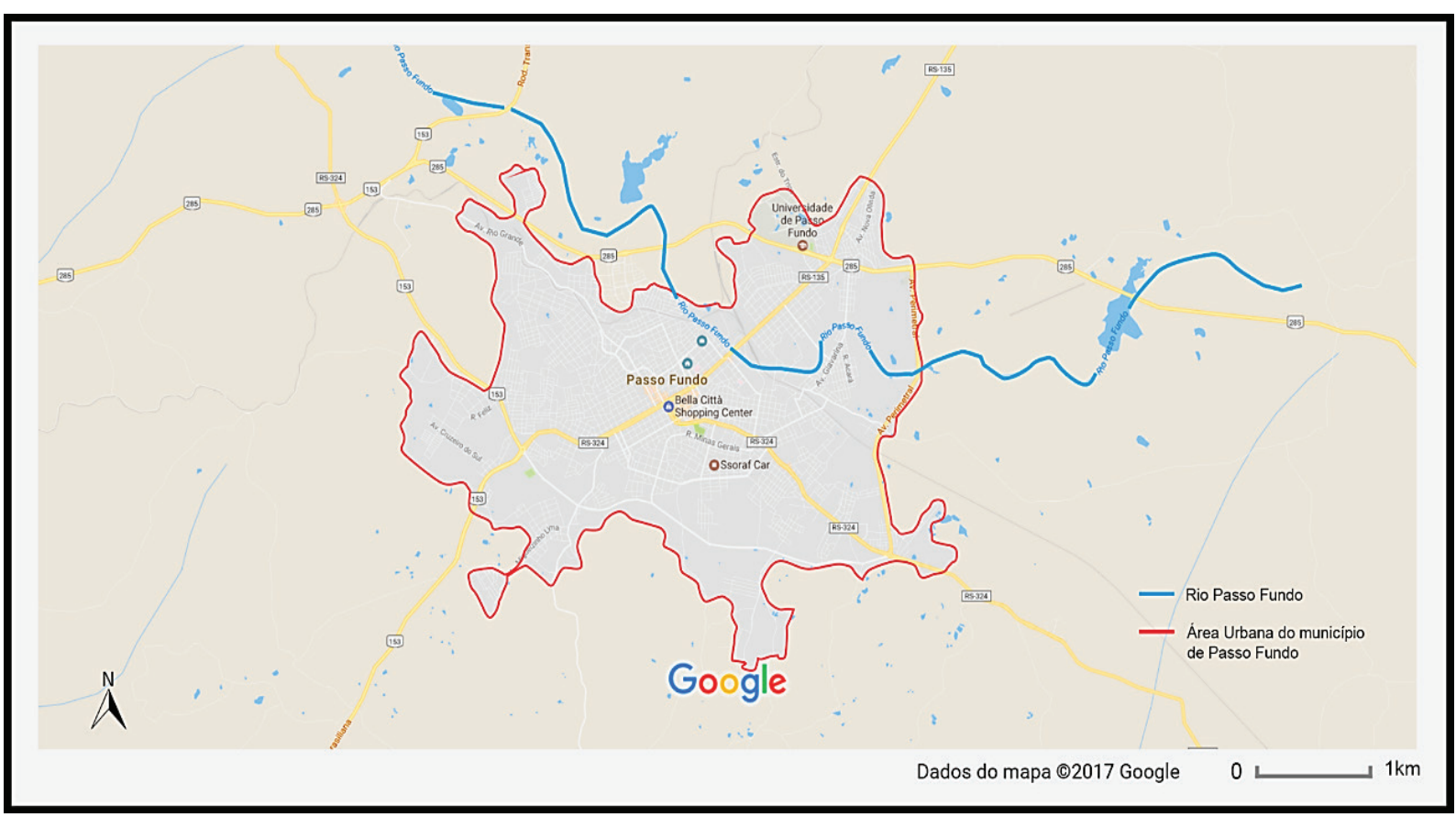

Fonte: Google Maps, 2017. Adaptado pela autora.

Assim, configurar-se-á uma região de estudo, definida não apenas pela presença do rio ou pelos limites político-administrativos do município, mas principalmente pelas interaçóes sociais e usos humanos desse ambiente Foram dois os critérios escolhidos para definir a regiáo que compreende a pesquisa sobre o rio Passo Fundo a partir dos conceitos fundamentais retirados da História Regional e da História Ambiental. O primeiro considera o recorte da extensão do rio desde a sua nascente, passando pelo território municipal, seja ele urbano ou rural. Esse é então, um recorte predominantemente biofísico, pois considera o trajeto feito pelo rio. Porém é importante analisar que, ao longo do tempo, principalmente na área urbana do município, esse trajeto e seu entorno sofreram alteraçôes humanas (canalizaçóes, pontes, edificações, etc.) de acordo com as necessidades sentidas por essas populaçóes. Quanto a isso a autora Ilsyane do Rocio Kmitta (2010, p. 16) afirma que:

Nesseamálgamaderelaçóes, oshomens modificama paisagem, operam transformaçóes, reordenam o espaço ao seu redor e são modificados por ele. Tal rede de relaçóes não se explica apenas ou somente pelo aspecto político, mas, também, pelo aspecto social, religioso, cultural e econômico. 
Sendo assim, as alterações geradas pelos seres humanos no ambiente podem ser pensadas como paisagens culturais, que surgem a partir das complexas relaçóes estabelecidas entre a sociedade e o ambiente. O segundo critério utilizado considera as relações estabelecidas entre a população e o rio, porque, como afirmou o geógrafo Milton Santos, "o espaço é igual à paisagem mais a vida nela existente; é a sociedade encaixada na paisagem, a vida que palpita conjuntamente com a materialidade" (SANTOS, 1988, pp. 25-26). Portanto, o recorte regional para essa pesquisa definiu-se pela combinaçáo destes dois critérios, um biofísico e outro social, estabelecidos pelo contato humano com o ambiente em questáo.

\section{CONSIDERAÇÕES FINAIS}

A multiplicação de variadas temáticas e abordagens históricas, a partir da Escola dos Annales, fez muitos teóricos temerem o aparecimento de assuntos entendidos como "irrelevantes". Contudo, é importante destacar que náo existem assuntos irrelevantes, quando relacionados com o todo, articulando suas relaçóes especificas e abrangentes. Assim é, também, com a História Regional, é imprescindível relacioná-la com o contexto global. A autora Vera Alice Cardoso Silva muito bem destacou quero conceito de região depende da referência constante ao sistema global de relaçóes do qual foi recortado (SILVA, 1990,43). Consequentemente, o conceito de regiáo acaba não sendo estático, permitindo muitas possibilidades. Cabe então, ao pesquisador, compreender a abrangência desse conceito incluindo seus aspectos históricos, ecológicos, culturais, econômicos, psicológicos, etc. Além de ter clareza do que motiva a delimitação regional, também é importante que o pesquisador que procura fazer a interface entre História Regional e História Ambiental perceba, como ressaltou José Augusto Pádua, que "a história ambiental, como ciência social, deve sempre incluir as sociedades humanas" (PÁDUA, 2010, p. 97). Sendo assim, o estudo se tornará relevante do ponto de vista histórico se tiver, como elemento central, a relação entre homem e natureza. É muito importante que o historiador leve em consideraçáo a possibilidade de combinaçóes entre elementos naturais e culturais, entre o mundo biofísico e a ação humana, para a constituição da realidade. Todos esses elementos naturais, sociais e culturais, políticos e econômicos estão interligados e interferem direta ou indiretamente nas relaçóes humanas entre si e com o ambiente. Por fim, considera-se fundamental ter equilíbrio ao analisar a ligação entre os homens e a natureza, para que todos os diferentes aspectos inerentes a ela possam ser considerados em suas mais complexas influências mútuas. 


\section{REFERÊNCIAS E FONTES}

ALBUQUERQUE JR., Durval Muniz de. A invenção do Nordeste e outras artes. São Paulo: Cortez, 2009.

ARRUDA, Gilmar (Org.). A natureza dos rios:história, memória e territórios. Curitiba: UFPR, 2008.

BARRELLA, W.; PETRERE JR., M.; SMITH, W.S.; MONTAG, L.F.A. As relaçóes entre as matas-ciliares, os rios e os peixes. In: RODRIGUES, R.R. \& LEITÃO FILHO, H.F. Matas ciliares: Conservação e recuperação. EDUSP, 2. ed., São Paulo, pp.187-207, 2001.

BARROS, José D’Assunção. História, Espaço e Tempo: interações necessárias. Varia História, Belo Horizonte, v. 22, n. 36, pp. 460-476, 2006.

BLOCH, Marc L. B. Apologia da História, ou, O oficio do historiador. Rio de Janeiro: Zahar, 2001.

BOURDIEU, Pierre. O poder simbólico. Rio de Janeiro: Difel, 1998.

CABRAL, Diogo de Carvalho. A bacia hidrográfica como unidade de análise em história ambiental. Revista de História Regional, Ponta Grossa, v. 12, n. 1, pp. 133-162, 2007.

CAFRUNI, Jorge E. Passo Fundo das Missões: Estudo Histórico do Período Jesuítico. Passo Fundo: [s.n.], 1966.

CARBONARI, María Rosa. De como explicar la región sin perderse en el intento. Repasando y repensando la Historia Regional. História Unisinos. Sáo Leopoldo, v.13, n.1, pp.19-34, 2009.

CORAZZA, Jaqueline. Rios urbanos e o processo de urbanizaçáo: o caso de Passo Fundo - RS. 2008. 198 f.: Dissertação (Mestrado em Engenharia) - Universidade de Passo Fundo, 2008. Disponível em: <https://secure.upf.br/pdf/2008JaquelineCorazza.pdf>. Acesso em 8 jan. 2017.

DEAN, Warren. A luta pela borracha no Brasil: um estudo de história ecológica. São Paulo: Nobel, 1989.

DEAN, Warren. A ferro e fogo: a história e a devastação da Mata Atlântica brasileira. São Paulo: Cia. das Letras, 2004.

DRUMMOND, José Augusto. A história ambiental: temas, fontes e linhas de pesquisa. Estudos Históricos. Rio de Janeiro, v. 4, n. 8, pp. 177-197, 1991.

GOVERNO DO ESTADO DO RIO GRANDE DO SUL. Secretaria Estadual do Meio Ambiente - Departamento de Recursos Hídricos. Relatório Anual Sobre A Situaçáo Dos Recursos Hídricos No Estado Do Rio Grande Do Sul Edição 2007/2008. Porto Alegre, 2008. Disponível em: http://www.comiteibicui.com.br/artigos/Relatorio\%20Anual\%20 sobre $\% 20 \mathrm{a} \% 20$ situacao\%20dos\%20RH\%20no\%20Estado\%20do\%20RS\%20\%20edicao\%202007-2008.pdf. Acesso em 04 jan. 2017.

HEINSFELD, Adelar; BATISTELA, Alessandro. (Org.). Fazendo História Regional: Economia, espaço e sociedade. Passo Fundo: Méritos, 2010.

KMITTA, I. R. Experiências vividas, naturezas construídas: Enchentes no Pantanal (Porto 
Murtinho 1970-1990). 2010. Dissertação (Mestrado em História) - Faculdade de Ciências Humanas, Universidade Federal da Grande Dourados (UFGD), Dourados, MS.

LEONARDI, Víctor. Os historiadores e os rios: natureza e ruína na amazônia brasileira. Brasília: Paralelo 15/ Editora Universidade de Brasília, 1999.

MARTINEZ, Paulo Henrique. Brasil: desafios para uma história ambiental. Nómadas. Bogotá, n. 22, p. 26-35, 2005.

MEGALE, Januário Francisco. Alguns “ismos” das Ciências Sociais. Disponível em:<http://chafic.com.br/chafic/moodle/file.php/1/Biblioteca_Virtual/Temas_educacionais/ Alguns_ismos_das_Ciencias_Sociais_.pdf>.Acesso em: 9 jan. 2017.

MORAES, Antonio Carlos Robert. Geografia: Pequena História Crítica. 20. ed., São Paulo: Annablume, 2005.

NASH, R. American environmental history: a new teaching frontier. Pacific Historical Review, n. 41, pp. 362-372, 1972.

OLIVEIRA, Francisco Antonino Xavier e. Annaes do município de Passo Fundo. Passo Fundo: Ed. Universidade de Passo Fundo, 1990.

PÁDUA, José Augusto. As bases teóricas da História Ambiental. Estudos Avançados São Paulo, v. 24, n. 68, 2010.

PREFEITURA MUNICIPAL DE PASSO FUNDO. Plano ambiental municipal de Passo Fundo. Passo Fundo: Prefeitura Municipal de Passo Fundo, 2004.

RAFFESTIN, Claude. Por uma Geografia do Poder. Tradução de Maria Cecília França. São Paulo: Ática, 1993.

RIBEIRO, Rafael Winter. Seca e Determinismo: a Gênese do Discurso do Semiárido Nordestino.Anuário do Instituto de Geociências - UFRJ.Rio de Janeiro, v. 22, 1999.

SANTOS, Milton. Metamorfoses do espaço habitado: fundamentos teóricos e metodológicos da geografia. Sáo Paulo: Hucitec, 1988.

SANTOS, Milton. Espaço e método. 4. ed. São Paulo: Nobel, 1997.

SANTOS, Milton. A natureza do espaço: técnica e tempo, razão e emoção. 4. ed. São Paulo: EDUSP, 2002.

SILVA, Vera Alice Cardoso. Regionalismo: o enfoque metodológico e a concepção histórica. In: SILVA, Marcos A. da (coord.). República em migalhas: história regional e local. São Paulo: Marco Zero, 1990.

VESENTINI, J. W. O ensino de Geografia no Brasil: uma perspectiva histórica. In: VESENTINI, José William (Org.). O ensino de Geografia no século XXI. Sáo Paulo: Papirus, 2004.

WORSTER, Donald. Para fazer história ambiental. Estudos Históricos, Rio de Janeiro: CPDOC/Fundação Getúlio Vargas, v. 4, n. 8, pp. 198-215, 1991.

Recebido: $26 / 6 / 2017$

Aceito: $28 / 9 / 2017$ 